University of Nebraska - Lincoln

DigitalCommons@University of Nebraska - Lincoln

6-1-1998

\title{
Nanostructured NdFeB films processed by rapid thermal annealing
}

M. Yu

University of Nebraska - Lincoln

Yi Liu

University of Nebraska-Lincoln, yliu@unl.edu

Sy_Hwang Liou

University of Nebraska-Lincoln, sliou@unl.edu

David J. Sellmyer

University of Nebraska-Lincoln, dsellmyer@unl.edu

Follow this and additional works at: https://digitalcommons.unl.edu/physicsliou

Part of the Physics Commons

Yu, M.; Liu, Yi; Liou, Sy_Hwang; and Sellmyer, David J., "Nanostructured NdFeB films processed by rapid thermal annealing" (1998). Si-Hwang Liou Publications. 70.

https://digitalcommons.unl.edu/physicsliou/70

This Article is brought to you for free and open access by the Research Papers in Physics and Astronomy at DigitalCommons@University of Nebraska - Lincoln. It has been accepted for inclusion in Si-Hwang Liou Publications by an authorized administrator of DigitalCommons@University of Nebraska - Lincoln. 


\section{Nanostructured NdFeB films processed by rapid thermal annealing}

M. Yu, ${ }^{a}$, b) $Y . ~ L i u,{ }^{c}$ S. H. Liou, ${ }^{\text {a) }}$ and D. J. Sellmyer ${ }^{a)}$

Center for Materials Research and Analysis, University of Nebraska, Lincoln, Nebraska 68588-0113

Nanostructured $\mathrm{NdFeB}$ films were prepared by magnetron sputtering followed by rapid thermal annealing at a ramp rate of $200{ }^{\circ} \mathrm{C} / \mathrm{s}$. Isotropically oriented $\mathrm{Nd}_{2} \mathrm{Fe}_{14} \mathrm{~B}$ crystallites were formed in the films and coercivities up to $20 \mathrm{kOe}$ and remanence ratios up to 0.8 were obtained. Transmission electron microscopy analysis shows that the majority phase of the magnetic layer in the high coercivity films consists of $\mathrm{Nd}_{2} \mathrm{Fe}_{14} \mathrm{~B}$ nanocrystallites with an average size of about $50 \mathrm{~nm}$. These nanocrystallites are believed to be single-domain particles, which are responsible for the high coercivities. MFM measurements show that the domain size is about $500 \mathrm{~nm}$. It is thus indicated that the $50 \mathrm{~nm} \mathrm{Nd}{ }_{2} \mathrm{Fe}_{14} \mathrm{~B}$ nanocrystallites are strongly exchange-coupled into the $500 \mathrm{~nm}$ domains and the high remanence ratio originates from this exchange coupling. (C) 1998 American Institute of Physics. [S0021-8979(98)44111-2]

\section{INTRODUCTION}

Since the discovery of $\mathrm{Nd}_{2} \mathrm{Fe}_{14} \mathrm{~B}$ in $1984,{ }^{1-3}$ numerous studies on NdFeB-based materials have been conducted to obtain a better understanding of their excellent intrinsic properties and develop better fabrication processes for permanent magnets. ${ }^{4}$ Most of this research was on bulk NdFeB materials and relatively only a little work has been done on thin film $\mathrm{NdFeB}$ materials. ${ }^{5-13}$ With the rapid development of micromechanical devices, microelectronics, and integrated magnetoelectronic devices, applications of permanent magnet films are becoming more significant. Furthermore, better knowledge of $\mathrm{NdFeB}$ films also can help one to understand the exchange coupling in nanostructured magnetic materials because films thickness and grain sizes can be controlled to some extent to test some recent theoretical calculations. ${ }^{14,15}$

In this article we report our systematic study of the magnetic properties of nanostructured $\mathrm{NdFeB}$ films prepared from amorphous state by rapid thermal annealing (RTA). RTA features a very high ramp rate $\left(200{ }^{\circ} \mathrm{C} / \mathrm{s}\right)$ and thus is able to anneal films for a very short effective annealing time (tens of seconds), which is essential in forming isotropic nanostructured $\mathrm{NdFeB}$ films with high coercivities $\left(H_{c}\right)$ and high remanence ratios $\left(M_{r} / M_{s}\right)$.

\section{EXPERIMENTAL METHODS}

All NdFeB films were deposited directly onto watercooled 7059 glass substrates at room temperature by dc magnetron sputtering with base pressure of better than 3 $\times 10^{-7}$ Torr and Ar pressure of $10 \mathrm{mTorr}$. The NdFeB layer has a thickness of $500 \mathrm{~nm}$ and is protected by a $40 \mathrm{~nm} \mathrm{Cr}$ overcoat. The $\mathrm{Nd}_{15} \mathrm{Fe}_{77} \mathrm{~B}_{8}$ target was provided by Electron Energy Company and some $\mathrm{Nd}$ chips were added to adjust the $\mathrm{Nd}$ concentration. The composition of the films is $\mathrm{Nd}_{30} \mathrm{Fe}_{63} \mathrm{~B}_{7}$, which was estimated by the area ratio of $\mathrm{Nd}$ chips and the target and verified by energy-dispersive $\mathrm{x}$-ray measurements. The as-deposited films were all processed by

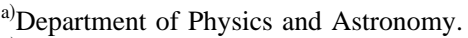

${ }^{b}$ Electronic mail: myu@unlinfo.unl.edu

${ }^{c)}$ Department of Mechanical Engineering.
}

RTA technique (unless specified otherwise) in flowing Ar with a ramp rate of $200^{\circ} \mathrm{C} / \mathrm{s}$. The structure and microstructure were characterized by $\mathrm{x}$-ray diffraction (XRD) and transmission electron microscopy (TEM) measurements. The magnetic properties at room temperature were determined by a SQUID magnetometer and the magnetic domain size was estimated by MFM measurements.

\section{RESULTS AND DISCUSSION}

The XRD pattern of an as-deposited $\mathrm{NdFeB}$ film is shown in Fig. 1. Magnetic measurements showed that the as-deposited films are magnetically soft. It is thus indicated as expected that the as-deposited films are amorphous except for the presence of a little $\alpha$-Fe. Figure 1 also shows the XRD pattern of the $\mathrm{NdFeB}$ film annealed at $500{ }^{\circ} \mathrm{C}$ for $60 \mathrm{~s}$. $\mathrm{Nd}_{2} \mathrm{Fe}_{14} \mathrm{~B}$ crystallites were formed and they were found to be isotropically oriented in the annealed film, as indicated by the peaks in Fig. 1. In fact all properly annealed films (i.e.,

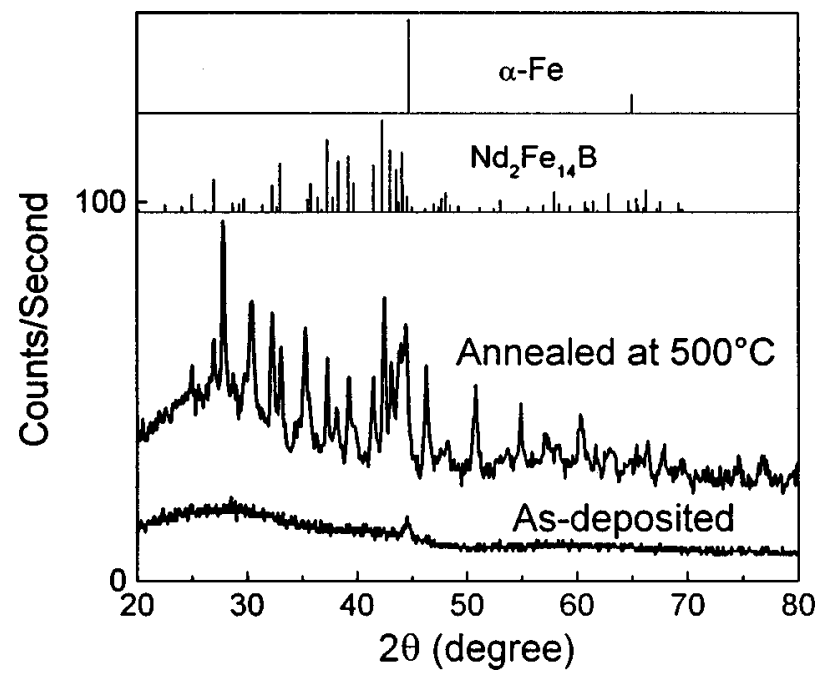

FIG. 1. X-ray diffraction patterns of as-deposited and annealed $\left(500{ }^{\circ} \mathrm{C}, 60\right.$ s) $\mathrm{NdFeB}$ films. The standard diffraction patterns of $\alpha$-Fe and $\mathrm{Nd}_{2} \mathrm{Fe}_{14} \mathrm{~B}$ phases are also shown for comparison. 


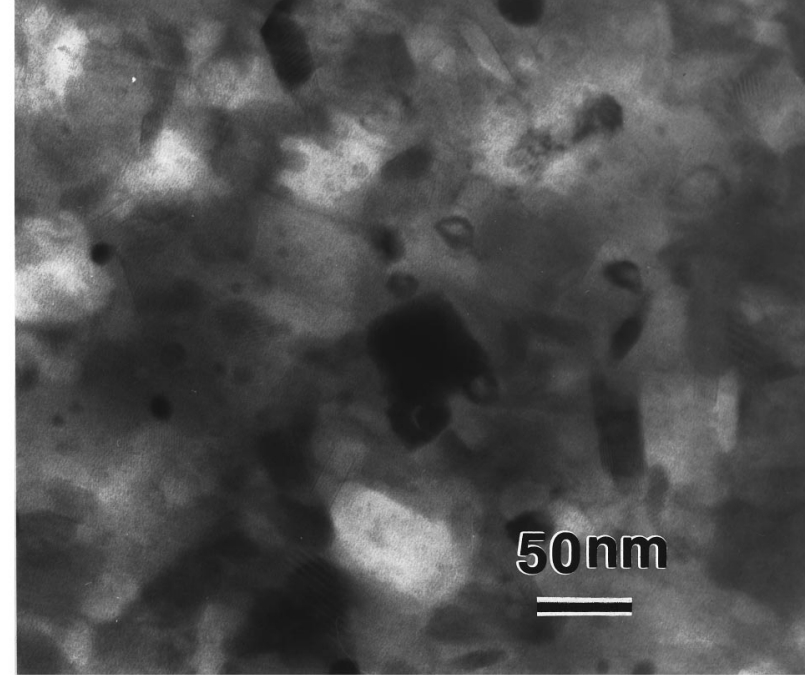

FIG. 2. TEM picture of a NdFeB film annealed at $500{ }^{\circ} \mathrm{C}$ for $60 \mathrm{~s}$.

those with $H_{c}>5 \mathrm{kOe}$ ) consist of isotropically oriented $\mathrm{Nd}_{2} \mathrm{Fe}_{14} \mathrm{~B}$ crystallites, as confirmed by both XRD and magnetic measurements (see later discussion).

The XRD pattern of the annealed $\mathrm{NdFeB}$ film has peaks other than those of $\mathrm{Nd}_{2} \mathrm{Fe}_{14} \mathrm{~B}$. They can all be indexed to $\mathrm{Nd}_{2} \mathrm{O}_{3}$ and $\mathrm{NdO}$ phases. The oxygen was mainly introduced in the RTA process which in our case can be done only in flowing Ar.

The formation of the $\mathrm{Nd}_{2} \mathrm{Fe}_{14} \mathrm{~B}$ phase is only one necessary condition to have high $H_{c}$ and $M_{r} / M_{s}$ in NdFeB films. The other is that appropriate microstructure must be developed. Figure 2 is the bright field TEM picture of the NdFeB film annealed at $500{ }^{\circ} \mathrm{C}$ for $60 \mathrm{~s}$. Electron diffraction analysis indicates that the grains shown in Fig. 2 are $\mathrm{Nd}_{2} \mathrm{Fe}_{14} \mathrm{~B}$ crystallites. The size of these crystallites is about $50 \mathrm{~nm}$. This means that these nanocrystallites are single-domain particles because the critical single-domain particle diameter of

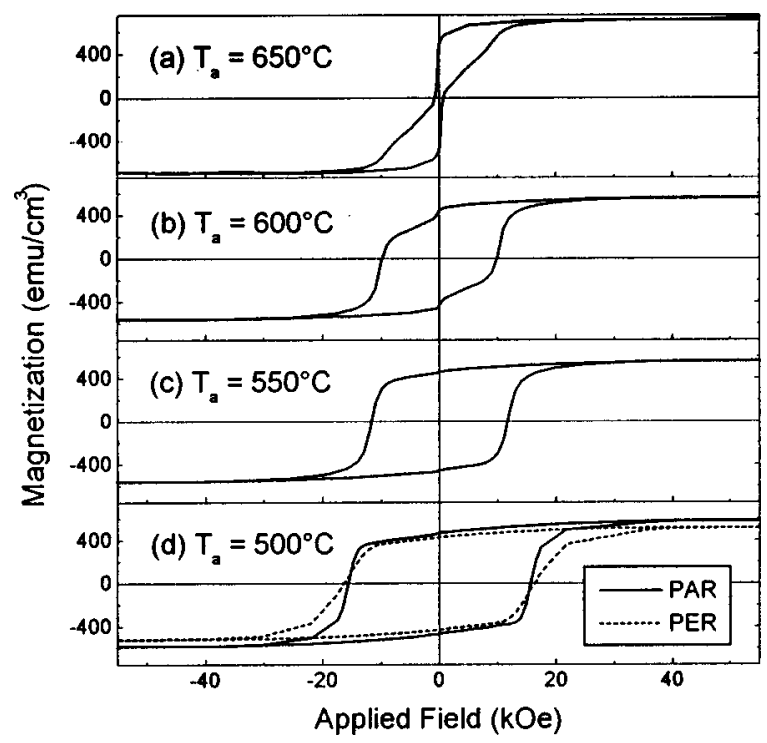

FIG. 3. Hysteresis loops of NdFeB films annealed for $60 \mathrm{~s}$ at various temperatures $\left(T_{a}\right)$.
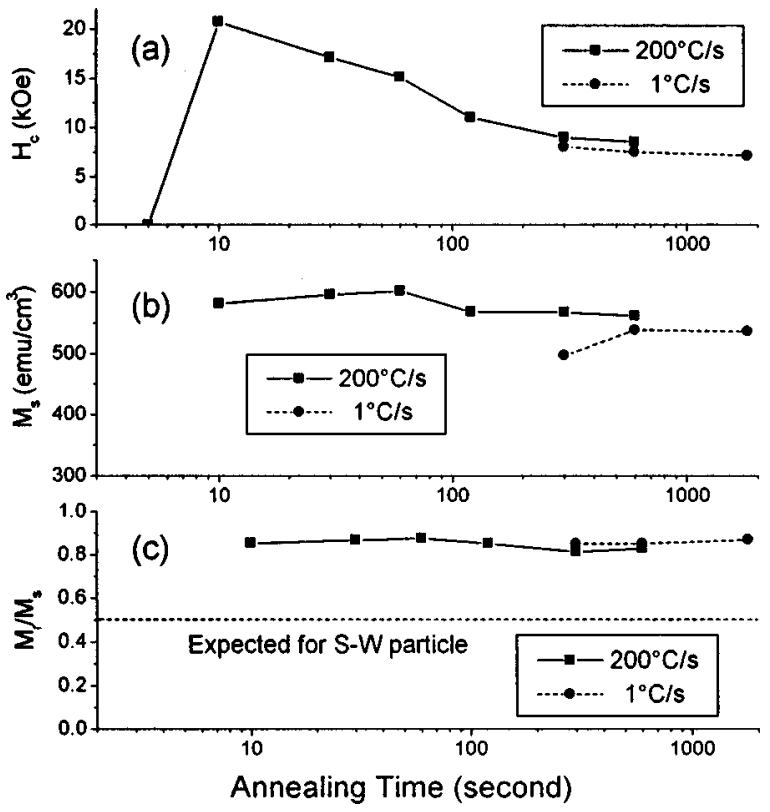

FIG. 4. (a) $H_{c}$, (b) $M_{s}$, and (c) $M_{r} / M_{s}$ of $\mathrm{NdFeB}$ films annealed at $550{ }^{\circ} \mathrm{C}$ for various times with ramp rates of 200 and $1{ }^{\circ} \mathrm{C} / \mathrm{s}$.

$\mathrm{Nd}_{2} \mathrm{Fe}_{14} \mathrm{~B}$ is about $300 \mathrm{~nm} .{ }^{4}$ The composition of the film indicates that there should be a thin Nd-rich layer between the nanocrystalline $\mathrm{Nd}_{2} \mathrm{Fe}_{14} \mathrm{~B}$ particles, although it cannot been seen due to limited resolution. The high ramp rate may also introduce some defects other than the Nd-rich layer.

With the change of structure and microstructure in $\mathrm{Nd}-$ FeB films, the magnetic properties are also changed completely after annealing. Figure 3(d) shows the parallel and perpendicular hysteresis loops of the $\mathrm{NdFeB}$ film annealed at $500{ }^{\circ} \mathrm{C}$ for $60 \mathrm{~s}$. The large $H_{c}(\sim 16 \mathrm{kOe})$ and the similarity of the two loops also indicate the formation of isotropically oriented $\mathrm{Nd}_{2} \mathrm{Fe}_{14} \mathrm{~B}$ nanocrystallites in a $\mathrm{Nd}-\mathrm{Fe}-\mathrm{B}$ system. In addition to the formation of the $\mathrm{Nd}_{2} \mathrm{Fe}_{14} \mathrm{~B}$ phase, the microstructure (the $50 \mathrm{~nm}$ nanocrystallites and the associated defects) also plays an important role in developing high $H_{c}$.

Annealing temperature $\left(T_{a}\right)$ and time $\left(t_{a}\right)$ can strongly affect the magnetic properties. Figure 3 shows the hysteresis loops of the $\mathrm{NdFeB}$ films annealed for $60 \mathrm{~s}$ at various $T_{a}$. We observed that no $H_{c}$ can be developed if $T_{a}<500{ }^{\circ} \mathrm{C}$. After $T_{a}$ reaches $500{ }^{\circ} \mathrm{C}, H_{c}$ is developed but decreases and the saturation magnetization $M_{s}$ changes slightly as $T_{a}$ increases. If $T_{a}>650{ }^{\circ} \mathrm{C}, H_{c}$ decreases sharply with a moderate increase of $M_{s}$. These results have the following implications. First, the crystallization of $\mathrm{Nd}_{2} \mathrm{Fe}_{14} \mathrm{~B}$ can occur only when $T_{a} \geqslant 500{ }^{\circ} \mathrm{C}$, which is less than $627^{\circ} \mathrm{C}$, the crystallization temperature of $\mathrm{Nd}_{2} \mathrm{Fe}_{14} \mathrm{~B} .{ }^{4}$ This is reasonable because the crystallization temperature decreases when $\mathrm{Nd}$ concentration increases. ${ }^{16}$ Second, when $T_{a}>500{ }^{\circ} \mathrm{C}$, presumably the $\mathrm{Nd}_{2} \mathrm{Fe}_{14} \mathrm{~B}$ nanocrystallites grow and the defects are reduced. This is the most probable reason for the decrease of $H_{c}$ with the increase of $T_{a}$. Finally when $T_{a} \geqslant 650^{\circ} \mathrm{C}$, most $\mathrm{Nd}$ is oxidized and $\alpha$-Fe is left as the main magnetic phase, causing the sharp decrease of $H_{c}$ and the increase of $M_{s}$.

Another batch of $\mathrm{NdFeB}$ films was annealed at $550{ }^{\circ} \mathrm{C}$ for various $t_{a}$ and the resulting $H_{c}, M_{s}$, and $M_{r} / M_{s}$ are 


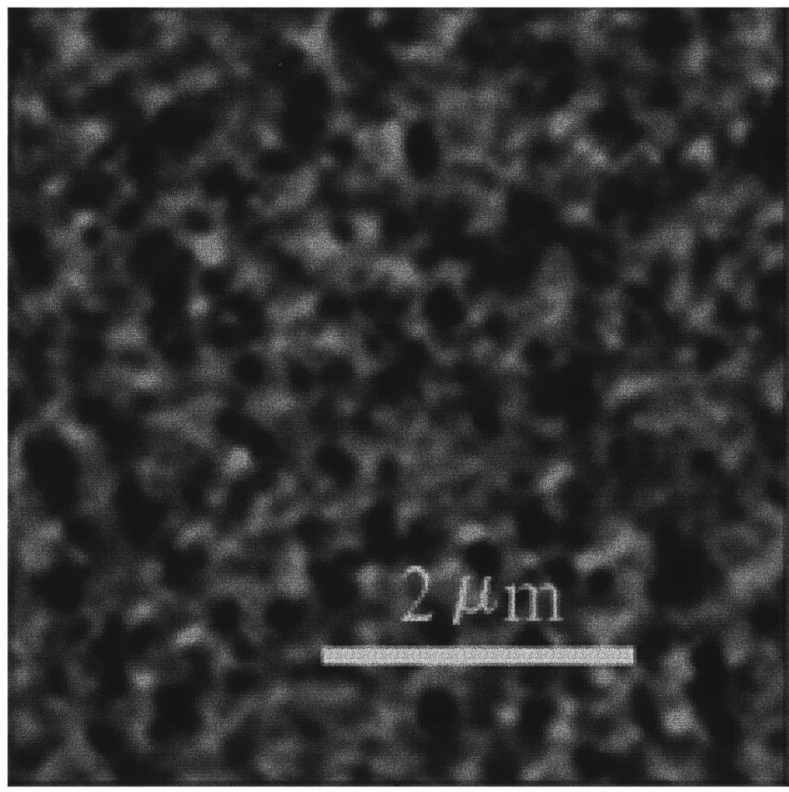

FIG. 5. MFM image of a thermally demagnetized NdFeB film annealed at $500{ }^{\circ} \mathrm{C}$ for $60 \mathrm{~s}$. The CoCr MFM tip was magnetized parallel to the sample surface.

plotted in Fig. 4. It is noted that $t_{a}$ has a strong effect on $H_{c}$ but a weak one on $M_{s}$. Short $t_{a}$ is critical to obtain high $H_{c}$, but $t_{a}<10 \mathrm{~s}$ is too short to achieve the proper crystallization of $\mathrm{Nd}_{2} \mathrm{Fe}_{14} \mathrm{~B}$ for high $H_{c}$. When $T_{a}>500{ }^{\circ} \mathrm{C}$, longer $t_{a}$ has essentially the same effect as higher $T_{a}$ on the microstructure, i.e., the $\mathrm{Nd}_{2} \mathrm{Fe}_{14} \mathrm{~B}$ nanocrystallites grow and the defects are reduced. In turn $H_{c}$ decreases and $M_{s}$ changes slightly as $t_{a}$ increases. The general effects of $T_{a}$ and $t_{a}$ on $H_{c}$ are in agreement with the results obtained in melt-spun $\mathrm{NdFeB}$ materials. ${ }^{16}$

For comparison we also annealed the as-deposited films at $550{ }^{\circ} \mathrm{C}$ in a conventional oven with a ramp rate of $1{ }^{\circ} \mathrm{C} / \mathrm{s}$. The resulting $H_{c}, M_{s}$, and $M_{r} / M_{s}$ are also shown in Fig. 4. Because of the low ramp rate, the total effective annealing time of the conventional oven is longer than that of RTA for the same $t_{a}$. Thus the $H_{c}$ obtained by the conventional oven is smaller than that obtained by RTA. This result clearly demonstrates the importance of high ramp rate when very short annealing time is needed.

We have shown that the $\mathrm{Nd}_{2} \mathrm{Fe}_{14} \mathrm{~B}$ nanocrystallites are isotropically oriented in the annealed films. According to Stoner-Wohlfarth theory ${ }^{17}$ such a system should have a $M_{r} / M_{s}$ of 0.5 if there is no interaction among the $\mathrm{Nd}_{2} \mathrm{Fe}_{14} \mathrm{~B}$ nanocrystallites. But Fig. 4(c) shows that these isotropic NdFeB films have $M_{r} / M_{s}>0.8$. The high $M_{r} / M_{s}$ must come from the strong exchange coupling among the $\mathrm{Nd}_{2} \mathrm{Fe}_{14} \mathrm{~B}$ nanocrystallites. This phenomenon was observed in meltspun isotropic $\mathrm{NdFeB}$ materials ${ }^{18}$ and predicted in theoretical calculations. ${ }^{19}$ A MFM image of a thermally demagnetized $\mathrm{NdFeB}$ film annealed at $500{ }^{\circ} \mathrm{C}$ for $60 \mathrm{~s}$ is shown in Fig. 5. It can be estimated that the domain size is about $500 \mathrm{~nm}$. This means that in one domain there are many $\mathrm{Nd}_{2} \mathrm{Fe}_{14} \mathrm{~B}$ nanocrystallites aligned by exchange coupling. Such a micromagnetic structure (sometimes called "an interaction domain") provides a direct explanation for the high $M_{r} / M_{s}$. The exchange coupling here is so strong that $M_{r} / M_{s}$ is changed slightly when $H_{c}$ is changed dramatically.

\section{CONCLUSIONS}

By using the RTA technique we are able to fabricate isotropic nanocrystalline $\mathrm{NdFeB}$ films with high $H_{c}$ and high $M_{r} / M_{s} . H_{c}$ is very sensitive to annealing temperature and time. Low temperature and short time, which are just enough to crystallize the amorphous $\mathrm{NdFeB}$ into single-domain $\mathrm{Nd}_{2} \mathrm{Fe}_{14} \mathrm{~B}$ nanocrystallites, are critical to obtain the proper microstructure for high $H_{c}$. We also found that these high coercivity, nanocrystalline $\mathrm{NdFeB}$ films have very high $M_{r} / M_{s}$, which originates from the strong exchange coupling among the $\mathrm{Nd}_{2} \mathrm{Fe}_{14} \mathrm{~B}$ nanocrystallites.

\section{ACKNOWLEDGMENTS}

The authors would like to thank Professor R. D. Kirby and Dr. Z. S. Shan for their generous help. This work was supported by DOE and CMRA. S. H. Liou was also supported by ARO/DAAG55-98-1-0014.

${ }^{1}$ J. J. Croat, J. F. Herbst, R. W. Lee, and F. E. Pinkerton, J. Appl. Phys. 55, 2078 (1984)

${ }^{2}$ M. Sagawa, S. Fujimura, M. Togawa, H. Yamamota, and Y. Matsuura, J. Appl. Phys. 55, 2083 (1984).

${ }^{3}$ D. J. Sellmyer, A. U. Ahmed, and G. C. Hadjipanayis, J. Appl. Phys. 55, 2088 (1984).

${ }^{4}$ J. F. Herbst, Rev. Mod. Phys. 63, 819 (1991).

${ }^{5}$ F. J. Cadeu, T. D. Cheung, and L. Wickramasekara, J. Magn. Magn. Mater. 54-57, 535 (1986).

${ }^{6}$ K. D. Aylesworth, Z. R. Zhao, D. J. Sellmyer, and G. C. Hadjipanayis, J. Appl. Phys. 64, 5742 (1988).

${ }^{7}$ J. F. Zasadzinski, C. U. Segre, and E. D. Rippert, J. Appl. Phys. 61, 4278 (1987).

${ }^{8}$ H. Homburg, Th. Sinnemann, S. Methfessel, M. Rosenberg, and B. X. Gu, J. Magn. Magn. Mater. 83, 231 (1990).

${ }^{9}$ B. A. Kapitanov, N. V. Komilov, Ya. L. Linestsky, and V. Yu. Tsvetkov, J. Magn. Magn. Mater. 127, 289 (1993).

${ }^{10}$ H. Lemke, S. Müller, T. Göddenhenrich, and C. Heiden, Phys. Status Solidi A 150, 723 (1995).

${ }^{11}$ S. Parhofer, G. Gieres, J. Wecker, and L. Schultz, J. Magn. Magn. Mater. 163, 32 (1996).

${ }^{12}$ H. Sun, T. Tomida, S. Hirsosawa, and Y. Maehara, J. Magn. Magn. Mater. 164, 18 (1996).

${ }^{13}$ D. J. Keavney, E. E. Fullerton, J. E. Pearson, and S. D. Bader, J. Appl. Phys. 81, 4441 (1997)

${ }^{14}$ R. Skomski and J. M. D. Coey, Phys. Rev. B 48, 15812 (1993).

${ }^{15}$ I. A. Al-Omari and D. J. Sellmyer, Phys. Rev. B 52, 3441 (1995).

${ }^{16}$ J. Wecker and L. Schultz, J. Appl. Phys. 62, 990 (1987).

${ }^{17}$ W. C. Stoner and E. P. Wohlfarth, Philos. Trans. R. Soc. London, Ser. A 240, 599 (1948)

${ }^{18}$ G. C. Hadjipanayis and W. Gong, J. Appl. Phys. 64, 5559 (1988)

${ }^{19}$ R. Fischer and H. Kronmüller, Phys. Rev. B 54, 7284 (1996). 